\title{
La Negación Clausal en Kari'ña y Otras Lenguas Caribes
}

\author{
Clause Negation In Kari'ña And Other Cariban Languages
}

\author{
José Ramón Álvarez González \\ Universidad del Valle (Campus Meléndez)
}

\begin{abstract}
Resumen. Este trabajo describe la negación clausal en kari'ña, lengua caribe hablada en Venezuela, y examina si un análisis similar es posible para otras lenguas de la misma familia. En sus estudios morfológicos y léxicos sobre kari'ña, Jorge Mosonyi $(1982,1986,2000,2002)$ incluye aisladas observaciones sintácticas donde plantea que la conjugación negativa se logra mediante una forma negativa invariable construida con el sufijo -ja añadido al tema verbal, y donde la flexión se expresa mediante formas flexionadas del verbo vañño 'estar'. Aunque esto es morfológicamente correcto, en su análisis sintáctico Mosonyi sostiene además que tal forma negativa tiene un valor predicativo en el sentido de que se trata de "una oración de predicado nominal" (1982, p. 144). Nuestro análisis difiere porque considera que tal sufijo negativo produce por derivación morfológica una transposición de toda la frase verbal, adverbializándola. Siendo adverbio, actúa como complemento del verbo vañño, y no como predicado nominal. Aunque soporta la flexión, vañño no es un verbo copulativo, porque no permite nunca predicación nominal, y funciona como un verbo intransitivo cualquiera. La negación mediante construcciones similares ha sido reportada en otras lenguas caribes: galibí (RÉNAULT-LESCURE, 1981), tamanaco (GILIJ, 1782), hixkaryana (DERBYSHIRE, 1985), makushi (ABBOTT, 1991), panare (MATTÉl-MÜLLER, 1994), pemón (ÁLVAREZ, 2000). Pese a diferencias mínimas, el examen de la negación clausal en estas lenguas permite destacar un mecanismo sintáctico considerablemente uniforme. Existe una forma negativa adverbial e invariable como base de toda la conjugación negativa, mientras que la flexión se expresa mediante diversas formas del verbo 'estar'. Las formas cognadas (kari'ña -ja, galibí - pa, tamanaco - pa, hixkaryana hira, makushi pra y pemón püra) actúan como transpositores puesto que ellos degradan una cláusula y la transponen funcionalmente a una unidad de rango inferior, en este caso a un adverbio, habilitándola para esta función.
\end{abstract}

Palabras clave: Kari'ña; Caribe; Sintaxis; Negación; Comparación.

\begin{abstract}
This work describes the clausal negation in Kari'ña, a Cariban language spoken in Venezuela, and examines whether a similar analysis is possible for other languages of the same family. In his morphological and lexical studies on kari'ña, Jorge Mosonyi $(1982,1986,2000,2002)$ includes isolated syntactic observations where he claims that the negative conjugation is achieved through an invariable negative form constructed with the suffix -ja added to the verbal theme, and where the inflection is expressed through inflected forms of the verb vañño 'be'. Although this is morphologically correct, in his syntactic analysis Mosonyi further argues that such a negative form has a predicative value in the sense that it is "a noun predicate sentence" $1982, p$. 144). Our analysis differs because we think that such negative suffix produces by morphological derivation a transposition of the entire verb phrase, adverbializing it. Being an adverb, it acts as a complement of the verb vañño, and not as a nominal predicate. Although it supports inflection, vañño is not a copulative verb, because it never allows nominal predication, and works like any intransitive verb. Negation through similar constructions has been reported in other Cariban languages: Galibí (RÉNAULT-LESCURE, 1981), Tamanaco (GILIJ, 1782), Hixkaryana (DERBYSHIRE, 1985), Makushi (ABBOTT, 1991), Panare (MATTÉI-MÜLLER, 1994), Pemón (ÁLVAREZ, 2000). Despite minor differences, the examination of clause negation in these languages makes it possible to highlight a considerably uniform syntactic mechanism. There is an adverbial and invariable negative form as the basis of all the negative conjugation, while the inflection is expressed through various forms of the verb 'be'. The cognate forms (Kari'ña -ja, Galibí -pa, Tamanaco - pa, Hixkaryana hira, Makushi pra and Pemón püra) act as transposers since they degrade a clause and functionally transpose it to a lower rank unit, in this case to an adverb, enabling it for this function.
\end{abstract}

Keywords: Kari'ña; Cariban; syntax; negation; comparison 


\section{Una primera aproximación a la negación clausal en kari’ña}

Semánticamente se entiende como negación una operación que cambia el valor de verdad de una proposición en su opuesto. En una cláusula negativa generalmente se expresa que existe una situación, evento y estado de cosas opuesto a lo que se presupone. Existe también la negación de constituyentes de cláusulas, pero la estrategia más común y estudiada es la negación de una proposición completa, denominada "negación de cláusulas" o "negación de FV" (GIVÓN, 2001, p. 382). La negación de cláusulas puede realizarse por medios léxicos, morfológicos y analíticos (PAYNE, 1997, p. 282-294). La NEGACIÓN LÉXICA involucra verbos que intrínsecamente incluyen la negación dentro de su semántica (verbos como carecer). La NEGACIÓN MORFOLÓGICA se presenta cuando al verbo se añade un afijo que le invierte el semantismo (como el prefijo ma- en los verbos activos de la lengua wayuu, lengua arahuaca de Venezuela y Colombia: mayonnajüinsalii 'no bailan', cf. ayonnajüshii 'bailan'). La negación analítica se realiza mediante partículas negativas (como el adverbio no en español), por lo común asociadas al verbo, o mediante verbos auxiliares negativos finitos (como también sucede en la lengua wayuu el verbo auxiliar nnojoluu 'no.haber/estar'): nnojoishii ayonnajüin 'no bailan'). Cuando se usa este segundo tipo de negación analítica, el verbo negativo toma las propiedades morfosintácticas de los verbos finitos, como la flexión y la posición, mientras que el verbo léxico aparece en forma de subordinación. Es común que las lenguas tengan más de una estrategia de negación. Para una visión tipológica de la negación en las cláusulas independientes declarativas con predicado verbal, remitimos a Miestamo (2005).

Nuestro interés se centrará en el mecanismo que opera en la negación de cláusulas en kari'ña, una lengua caribe hablada por cerca de $\mathbf{1 0 . 0 0 0 ~ p e r s o n a s ~ e n ~ e l ~ n o r e s t e ~ d e ~ V e n e z u e l a , ~ c o m p a r a ́ n d o l o ~ c o n ~}$ el mismo fenómeno en otras lenguas caribes. Los datos del kari'ña provienen fundamentalmente de las diversas obras de Jorge Mosonyi citadas en las referencias y de nuestro propio trabajo de campo. Los datos sobre la lengua pemón y la lengua wayuu provienen de nuestro trabajo de campo sobre esas lenguas. Los datos de otras lenguas caribes provienen de las fuentes citadas en las referencias. El kari'ña, morfológica y sintácticamente, es muy similar a lenguas genéticamente muy cercanas habladas en la Guayana Francesa, Surinam, Guyana y Brasil, aunque diversos procesos fonológicos y ciertas diferencias léxicas les confieran una diversidad superficial a las que, con toda seguridad, pueden ser considerados dialectos de una misma lengua. Por razones de espacio, otros tipos de negación no serán considerados aquí. El restringirnos a la negación de cláusulas nos permitirá, entre otras cosas, mostrar la relativa homogeneidad que exhibe este fenómeno en las lenguas caribes, sin pretender cubrir la variedad de formas de la negación que estas lenguas puedan utilizar. Observemos, en primer lugar, los ejemplos (1-6), que contienen pares de cláusulas afirmativas y negativas. ${ }^{1}$

1. Usamos la ortografía práctica desarrollada para el kari'ña, descrita en los trabajos más importantes sobre el kari'ña venezolano (MOSONYI, 1982, 1986, 2002; MEDINA TAMANAICO; MOSONYI, 1982). El inventario sonoro del kari'ña es relativamente simple, con valores muy parecidos a los del español, excepto cuando se indica entre paréntesis: VOCALES: a, e, i, o, u, ü (alta posterior no redondeada [m]); CONSONANTES: p, t, k,' (oclusiva glotal [?], j (fricativa glotal [h]), s, sh

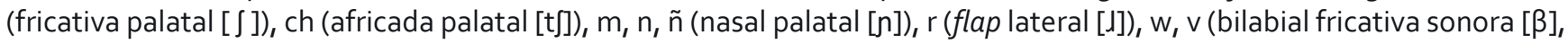
y [j], d (dental sonora [ð]). Las vocales dobles representan vocales alargadas [V:]. Las vocales altas en secuencia con vocales no altas suenan: [j], [w], [w]. Para las otras lenguas, excepto el pemón, se ha respetado la escritura de las fuentes. 
(1a)
Waanü no'nüki kaneekaneeta.
Wanü n-o'nükü-i kanekane-ta ${ }^{2}$
Juan 3-dormir-PAS chinchorro-en
Juan durmió en el chinchorro.

(1b)

$\begin{array}{llll}\text { Waanü kaneekaneeta } & \text { o'nüküja } & \text { ne'i. } \\ \text { Wanü kanekane-ta } & \text { o'nükü-ja } & \text { n-ai-i } \\ \text { Juan } & \text { chinchorro-en } & \text { dormir-neg } & \text { 3-estar-pas }\end{array}$

Juan no durmió en el chinchorro.

(2a)

$\begin{array}{llll}\text { Duumü } & \text { würüppuota } & \text { Waanü eenei. } \\ \text { ü-dumü } & \text { würüpo-ta } & \text { Wanü } & \varnothing \text {-ene-i } \\ \text { 1-padre } & \text { monte-en } & \text { Juan } & \text { 3/3-ver-PAS } \\ \text { Mi papá vio a Juan en el monte. } & \end{array}$

(2b)

\begin{tabular}{|c|c|c|c|c|}
\hline Duumü & würüppuota & Waanü & aneeneja & ne'i. \\
\hline ü-dumü & würüpo-ta & Wanü & an-ene-ja & $n-a i-i$ \\
\hline 1-padre & monte-en & Juan & 30-ver-neg & 3-estar-pas \\
\hline
\end{tabular}

(3a)

$\begin{array}{lll}\text { Poopuruppuo } & \text { areepa } & \text { sepeemai. } \\ \text { popuru-po } & \text { arepa } & \text { s-epema-i } \\ \text { pueblo-en } & \text { cazabe } & \text { 1/3-comprar-PAS } \\ \text { Compré cazabe en el pueblo. }\end{array}$

(3b)

$\begin{array}{llll}\text { Poopuruppuo } & \text { areepa } & \text { epemaja } & \text { ve'i. } \\ \text { popuru-po } & \text { arepa } & \text { epema-ja } & \text { v-ai-i } \\ \text { pueblo-en } & \text { cazabe } & \text { comprar-neg } & \text { 1-estar-pas }\end{array}$

No compré cazabe en el pueblo.

2. Se utilizan las siguientes convenciones en las glosas morfémicas: $0=$ cero persona/indefinido, $1=$ primera persona, $1+2=$ primera plural inclusiva, $1+3=$ primera persona plural exclusiva, $1 S=$ primera persona singular, $1 / 3=$ sujeto de primera persona y objeto de tercera, $3 / 3=$ sujeto y objeto de tercera persona, $3=$ tercera persona, $3 \mathrm{O}=$ objeto de tercera persona, $3 \mathrm{~S}$.PRES= tercera persona singular presente, $A D I C=$ adición, $A D V E R S=$ adversativo, $A N I=$ animado, AR= adverbializador, AUX= auxiliar, AUX.

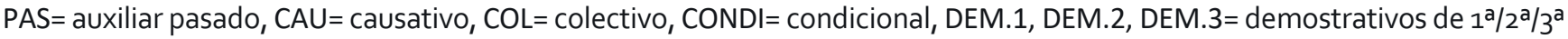
zona de la deixis, DES= desiderativo, DIST= distal, DTR= destransitivizador, ERG= ergativo, F= femenino, FN= frase nominal, FUT= futuro, IMP= imperativo, INAN= inanimado, IND= indefinido, $M=$ masculino, NEG= negador, NR:INST= nominalizador instrumental, $\mathrm{NR}: \mathrm{O}=$ nominalizador de objeto, $\mathrm{PAS}=$ pasado, $\mathrm{PLU}=$ plural, $\mathrm{POS}=$ posesivo, $\mathrm{POTEN}=$ potencial, $\mathrm{PRES}=$ presente, PRO:1= pronombre de primera persona, PRO:2= pronombre de segunda persona, PRO:13= pronombre de segunda persona de plural exclusivo, $\mathrm{PRO}: 3 \mathrm{P}=$ pronombre de tercera persona de plural, $\mathrm{PROX}=$ proximal, $\mathrm{RF}=$ reflexivo, $\mathrm{SB}=\mathrm{subordinado}, \mathrm{SIM}=$ simultaneidad, SUP= supino, TAM= tiempo/aspecto/modo. En los cortes morfémicos hemos revertido los procesos fonológicos que operan (alargamientos y geminaciones yámbicos, palatalizaciones, reducción silábica, epéntesis, metátesis, etc.), pero no podemos justificar tales procesos aquí y, para tal propósito remitimos a la bibliografía, en especial Álvarez (2004). 
(4a)

$\begin{array}{lll}\text { Dopooto } & \text { wüküürüdan } & \text { epoori. } \\ \text { dopoto } & \text { wükürü-yan } & \varnothing \text {-eporü-i } \\ \text { jefe } & \text { hombre-PLU } & 3 / 3 \text {-encontrar-PAS }\end{array}$

El jefe encontró a los hombres.

(4b)

$\begin{array}{llll}\text { Dopooto } & \text { wüküürüdan } & \text { epoorüja } & \text { ne'i. } \\ \text { dopoto } & \text { wükürü-yan } & \text { eporü-ja } & \text { n-ai-i } \\ \text { jefe } & \text { hombre-plu } & \text { encontrar-neg } & \text { 3-estar-pas } \\ \text { El jefe no encontró a los hombres. } & \end{array}$

(5a)
$N a^{\prime} n a$ keere nipijshai.
na'na kere n-pika-i
pro:13 yuca 3/3-pelar-pas
Nosotros pelamos la yuca.

(5b)

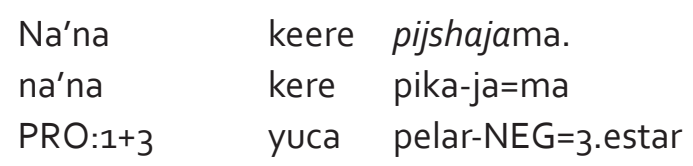

Nosotros no pelamos la yuca.

(6a)
Amaaro wojkaae.
a-maro ü-ojka-e
2-con 1-casar-pres
Me caso contigo.

(6b)

$\begin{array}{lll}\text { Amaaro } & \text { ojkaja } & \text { aauwa. } \\ \text { a-maro o } & \text { jka-ja } & \text { au=va } \\ \text { 2-con } & \text { casar-neg } & \text { pro:1=1.estar } \\ \text { Yonome caso contigo. } & \end{array}$

Una comparación de las estructuras presentes en estas cláusulas revela un claro patrón común. En las cláusulas afirmativas el único verbo lleva todos los elementos de la flexión: un prefijo como marca de persona/número, y un sufijo como marca de tiempo. En las cláusulas negativas, están presentes dos verbos, uno de los cuales es el verbo léxico en una forma negativa sin flexión TAM con el sufijo -ja, y otro es el vañño 'estar', el cual exhibe todos los elementos de la flexión, esto es, un prefijo como la marca de persona/número, y un sufijo como marca de tiempo. Este verbo, altamente irregular (ver sección 2.1), puede ser una palabra fonológica independiente, como en (1b-4b), o unirse como clítico al verbo negado si el auxiliar consta de una sola sílaba ( $5 b-6 b)$. 
La negación con un verbo auxiliar no es extraña en las lenguas. Por ejemplo, en la lengua wayuu, una de las principales formas de negación consiste en usar un verbo auxiliar negativo nnojoluu 'no.haber/estar' que toma toda la flexión (tiempo, marca de sujeto, etc.), mientras que el verbo léxico se subordina a él (7b).

(7a)

$\begin{array}{lll}\text { Ayonnajeechi } & \text { Kamiirü } & \text { watta'a. } \\ \begin{array}{l}\text { a-yonnaja-ee-chi } \\ \text { o-bailar-fut-m }\end{array} & \text { Kamiirü } & \text { watta'a } \\ \text { Camilo } & \text { mañana }\end{array}$

Camilo bailará mañana.

(7b)

$\begin{array}{llll}\text { Nnojoleechi } & \text { ayonnajüin } & \text { Kamiirü } & \text { watta'a. } \\ \text { nnojolu-ee-chi } & \text { a-yonnaja-in } & \text { Kamiirü } & \text { watta'a } \\ \text { no.estar-fut-m } & \text { o-bailar-sub } & \text { Camilo } & \text { mañana }\end{array}$

Camilo no bailará mañana.

En inglés tenemos una situación parecida. Se observa en los ejemplos (8-9), que en esta lengua el auxiliar do toma la marca de tercera persona singular del presente (8b), así como la marca de tiempo pasado ( $g b)$, y también atrae la marca de negación not. En este sentido, el peso de la flexión pasa del verbo léxico (speak 'vivir', walk 'caminar') al verbo auxiliar (do, does, did). Una diferencia obvia con el kari'ña y el wayuu es que el verbo léxico inglés retorna a su forma no flexionada, mientras que el verbo léxico kari'ña es el que lleva la negación mediante un proceso de sufijación de -ja, y en wayuu el verbo léxico se subordina con -in:

$$
\begin{array}{lll}
\text { John } & \text { speaks } & \text { English very well. } \\
\text { John } & \text { speak-s } & \text { English very well } \\
\text { Juan hablar-3s.pres } & \text { inglés muy bien } \\
\text { Juan habla inglés muy bien. }
\end{array}
$$

$\begin{array}{llll}\text { John doesn't } & \text { speak } & \text { English very well. } \\ \text { John } & \text { do-s-not } & \text { speak } & \text { English very well } \\ \text { Juan } & \text { aux-3s.pres-neg } & \text { hablar } & \text { inglés muy bien }\end{array}$

(9a)

$\begin{array}{ll}\text { Mary walked } & \text { today. } \\ \text { Mary walk-ed } & \text { today } \\ \text { María caminar-pas } & \text { hoy } \\ \text { María caminó hoy. } & \end{array}$

(9b)

$\begin{array}{llll}\text { Mary } & \text { didn't } & \text { walk } & \text { today. } \\ \text { Mary } & \text { did-not } & \text { walk } & \text { today } \\ \text { María } & \text { aux.pas-neg } & \text { caminar } & \text { hoy }\end{array}$




\section{La morfología de la construcción negativa en kari'ña}

En esta sección nos dedicaremos a examinar en detalle los elementos que entran enjuego en la estructura morfológica de la construcción negativa en kari'ña. Dedicaremos bastante atención a la presencia de diversos procesos fonológicos que originan un abundante alomorfismo en estos elementos.

\subsection{El verbo vañño 'estar'}

El verbo vañño 'estar' es sin duda el más importante para el sistema verbal en kari'ña. Tal preeminencia fue ya reconocida por los primeros estudiosos de esta lengua y lenguas relacionadas, quienes destacaron su importante y multiforme función como auxiliar (TARADELL, 1928 [1774], p. 285 para kari'ña, y TAUSTE, 168o, p. 51-53 para cumanagoto). Como sucede en muchas lenguas, se trata de un verbo altamente irregular, cuya raíz presenta diversos alomorfos producto de la interacción de complejos procesos fonológicos. Obsérvense algunas de tales irregularidades en la Tabla 1 (presente) y la Tabla 2 (pasado):

Tabla 1: Presente del verbo vañño

\begin{tabular}{|l|l|l|l|l|}
\hline ARG & \multicolumn{2}{|l|}{ Singular } & Plural \\
\hline S & Forma & Glosa & Forma & Glosa \\
\hline 1 & $=$ wa & yo estoy & -- & -- \\
\hline 2 & maana & tú estás & mantu & vosotros estáis \\
\hline 3 & $=m a$ & él está & mantu & ellos están \\
\hline $1+2$ & kataae & tú y yo estamos & kataatu & vosotros y yo estamos \\
\hline $1+3$ & na'na=ma & él/ellos y yo estamos & -- & -- \\
\hline
\end{tabular}

Nótese que las formas 1, 3 y 1+3 del presente están formadas por una sílaba liviana y, debido a una restricción de que la palabra mínima debe contener dos moras, las mismas están impedidas de aparecer como palabras fonológicamente independientes, y ellas forzosamente se unen como clíticos (indicados con =) a la palabra precedente, generalmente el sujeto. En esta tabla y la siguiente, la forma correspondiente a la $1^{a}$ persona exclusiva se da aparte, con el pronombre na'na, aunque su concordancia, como se observa, se da en la tercera persona.

Tabla 2: Pasado del verbo vañño

\begin{tabular}{|l|l|l|l|l|}
\hline ARG & \multicolumn{2}{|l|}{ Singular } & Plural \\
\hline S & Forma & Glosa & Forma & Glosa \\
\hline 1 & $v e^{\prime} i$ & yo estuve & -- & -- \\
\hline 2 & $m e^{\prime} i$ & tú estuviste & matchu & vosotros estuvisteis \\
\hline 3 & $n e^{\prime} i$ & él estuvo & natchu & ellos estuvieron \\
\hline $1+2$ & kete'i $^{\prime}$ & tú y yo estuvimos & katatchu & vosotros y yo estuvimos \\
\hline $1+3$ & $n a^{\prime}$ na ne'i & él/ellos y yo estuvimos & -- & -- \\
\hline
\end{tabular}

Hay que resaltar que, aunque este verbo vañño comúnmente aparece en la construcción negativa, ocasionalmente el mismo puede estar ausente en contextos pragmáticos apropiados, como ya lo apuntó Taradell (1774, p. 286): 
El pagua ô pava final, que es el verbo substantivo, de quien pende la divisa de los tiempos, tambien pro libito, se omite (retento $p a$ ), y mas q.do otro verbo indica el tiempo ô persona de la oracion; y usando de la mutilacion previa y posterior, como real.te se usa, conviene no omitir el pronombre para evitar confusion, y reducida esta nota 5.a a la practica, es assi: An: Apoypa, pro Anapoypava... No cojo. - Opapa, pro Oppapava... No vengo. (Subrayado nuestro) ${ }^{3}$

\section{2. El gerundio negativo y su estructura morfológica}

El gerundio negativo puede entenderse como un participio, ya que en general los participios son derivados verbales que se usa para modificar un nombre, una frase nominal, un verbo o frase verbal, tal como la haría un adjetivo o adverbio. El participio "participa" de una doble condición, ya que exhibe propiedades morfosintácticas de los adjetivos/adverbios como también de los verbos. Aunque en kari'ña no muestran tiempo, estos participios adverbiales (gerundios) sí toman argumentos como un verbo, dando origen a frases verbales participiales. En este gerundio negativo los argumentos indexados son los absolutivos (objetos de verbos transitivos y sujetos de verbos intransitivos), característica que comparte con el llamado "infinitivo". En la siguiente tabla se ofrecen las diversas formas que puede tomar el gerundio negativo en kari'ña, usando como ejemplo el verbo transitivo aroorü 'llevar', y proporcionand o cortes morfémicos. Nótese que hemos indicado con "FN" aquellas formas que se usan con frases nominales plenas y no con afijos personales. La raíz de este verbo tiene alomorfos aroo aaro aro, con palpables diferencias en duración vocálica, debido a factores rítmicos:

Tabla 3: Gerundio negativo transitivo

\begin{tabular}{|c|c|c|c|c|}
\hline ARG & \multicolumn{2}{|l|}{ Singular } & \multicolumn{2}{|l|}{ Plural } \\
\hline $\mathrm{O}$ & Forma & Glosa & Forma & Glosa \\
\hline $\mathrm{N}$ & an-aaro-ja & sin llevar FN & an-aaro-ja-ññe & sin llevar FN \\
\hline 1 & dü-aaro-ja & sin llevarme & -- & -- \\
\hline 2 & ad-aaro-ja & sin llevarte & ad-aaro-ja-ññe & sin llevaros \\
\hline 3 & an-aaro-ja & sin llevarlo & an-aaro-ja-ññe & sin llevarlos \\
\hline $1+2$ & k-aroo-ja & sin llevar a ti y a mí & k-aroo-ja-ññe & $\begin{array}{l}\text { sin llevar a } \\
\text { vosotros v a mí }\end{array}$ \\
\hline $1+3$ & na'na aroo-ja & sin llevar a él y a mí & -- & -- \\
\hline $3 R$ & $t$-aro-ja & sin llevar a símismo & t-aro-ja-ññe & sin llevar a símismos \\
\hline
\end{tabular}

Nótese que en esta tabla los diversos prefijos se refieren al objeto. Nótese también que el sufijo de plural -ññe en el plural también se refiere al objeto. La expresión del sujeto se hace mediante la forma correspondiente del verbo vañño, donde también se expresa la flexión TAM:

$(10)=(2 b)$

$\begin{array}{lllll}\text { Duumü } & \text { würüppuota } & \text { Waanü } & \text { aneeneja } & \text { ne'i. } \\ \text { Ü-dumü } & \text { würüpo-ta } & \text { Wanü } & \text { an-ene-ja } & n \text {-ai-i } \\ \text { 1-padre } & \text { monte-en } & \text { Juan } & \text { 30-ver-NEG } & \text { 3-estar-PAS }\end{array}$

Mi papá no vio a Juan en el monte.

3. Tauste sobre el cumanagoto: "Hablando ahora del dicho Verbo Guaz, y sus compuestos, advierto, que es el mas essencial Verbo desta Lengua, y el mas practico, y assi conuiene estudiarle bien, y penetrarlo, porque con pocas vozes de otros Verbos, ô Terminos, y el tal Verbo Guaz se puede frassear, y hablar con elegancia, y aprovechamiento. [...] Y por ser tan necesario este Verbo Guaz, y su inteligencia, y la de sus compuestos, los dividirê en cinco Classes..." (Tauste 1680:51) 
Por su parte, el gerundio negativo de un verbo intransitivo obviamente tendrá un número reducido de formas, habida cuenta de que no puede recibir prefijos que se refieran a un objeto. Nótese también que el sufijo -ññe de plural es opcional y, si se quiere, redundante, ya que la pluralidad del sujeto ya está expresada en el verbo vañño (cf. MOSONYI, 1982, p. 47). Ilustramos con el verbo intransitivo vataarono 'pasear' (que es, a su vez, una forma destransitivizada del verbo aroorü 'llevar' visto arriba):

Tabla 4: Gerundio negativo intransitivo

\begin{tabular}{|l|l|l|l|l|}
\hline ARG & \multicolumn{2}{|l|}{ Singular } & Plural \\
\hline \multirow{2}{*}{$\mathrm{O}$} & Forma & Glosa & Forma & Glosa \\
\cline { 2 - 5 } $\mathrm{N}$ & ataaro-ja & sin pasear (uno) & ataaro-ja(-ññe) & sin pasear (varios) \\
\hline
\end{tabular}

$(11)=(1 b)$

$\begin{array}{llll}\text { Waanü } & \text { kaneekaneeta } & \text { o'nüküja } & \text { ne'i. } \\ \text { Wanü } & \text { kanekane-ta } & \text { o'nükü-ja } & \text { n-ai-i } \\ \text { Juan } & \text { chinchorro-en } & \text { dormir-neg } & \text { 3-estar-pas }\end{array}$

Juan no durmió en el chinchorro.

\section{3. El tema verbal}

Los verbos en kari'ña pueden clasificarse desde un punto de vista morfosintáctico, fonológico, y morfológico. El siguiente esquema muestra tal clasificación. Los verbos dados de ejemplo se presentarán en el infinitivo (con el sufijo -rü para transitivos y el sufijo -no para intransitivos) y serán segmentados morfológicamente para revelar el tema:

$\diamond$ Morfosintáctico: Se refiere a la capacidad que tiene el verbo de tomar uno (solo sujeto) o dos argumentos (sujeto y objeto), la cual también determina los tipos de prefijos personales que se utilizan. Como ejemplo de intransitivo tenemos: atajta-no 'escupir', y como ejemplo de transitivo tenemos: eneepü-rü 'traer'.

$\diamond$ Fonológico: Se refiere a las clases de sonidos que ocupan los extremos del tema verbal. El sonido inicial puede ser vocálico, como en apoo-rü 'tocar', o consonántico, como en tankarü 'clavar'. El sonido final del tema verbal puede ser una vocal inmutable (a/o/e/i), como en vataaro-no 'cazar', o una vocal caduca (u/ü), como en atookü-rü 'coser'. Esta clasificación fonológica de los verbos es fundamental para una descripción elegante de la morfofonología verbal del kari'ña, habida cuenta de los múltiples procesos fonológicos generadores de un abundante alomorfismo.

$\checkmark$ Morfológico: Se refiere a si el tema verbal se deriva o no de otro tema nominal o verbal por medio de la adición de prefijos o sufijos. Entre los temas deverbales sobresalen en esta lengua, así como en las otras lenguas caribes, los verbos destransitivizados con valor principalmente reflexivo, y los causativos: 


\begin{tabular}{llllll}
\multicolumn{2}{c}{ PRIMARIOS } & \multicolumn{2}{c}{ DERIVADOS } \\
aka'na-no & 'correr' & \multicolumn{2}{c}{ DENOMINALES } & \multicolumn{2}{c}{ DEVERBALES } \\
awwa-no & 'reír' & {$[$ varee-ta]-no } & 'cantar' & $v$-[e-kuupi]-ño & 'bañarse' \\
kuupi-rü & 'bañar' & {$[$ mün-ta]-no } & 'sangrar' & $v$-[at-aadu]-no & 'freírse' \\
apoo-rü & 'tocar' & {$[a j s h u-k a a]-r u ̈$} & 'exprimir' & {$[a p o o-p o]-r u ̈$} & 'hacer \\
amee-rü & 'lamer' & {$[$ evaa-ka]-rü } & 'descolgar' & [enee-po]-rü & 'tocar'
\end{tabular}

\subsection{El prefijo de objeto}

El gerundio negativo de un verbo transitivo suele llevar un marcador de objeto en la forma de un prefijo:

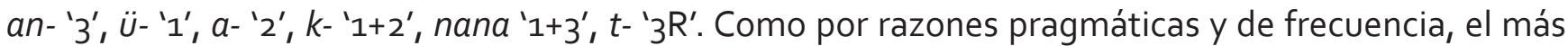
usado es el prefijo an- ' 3 ', examinaremos a continuación el gran impacto que tienen varios procesos fonológicos al darse la concatenación de este prefijo con el tema verbal. Se agruparán estas formas negativas según la interacción de estos procesos fonológicos. Las columnas contienen el infinitivo, la glosa, el gerundio negativo y el pasado de 1s. El primer miembro de cada columna contiene la segmentación morfológica como muestra:

Vocal inicial de tema + prefijo an- en simple concatenación (temas en $\mathbf{w}$ tienen /u/ subyacente):

$\begin{array}{llll}\text { aduu-ru } & \text { freír } & \text { an-aadu-ja } & \text { s-aadu-i } \\ \text { ajkotoorü } & \text { atajar } & \text { anajkotoja } & \text { sajkotoi } \\ \text { ajkuru } & \text { usar } & \text { anajkuja } & \text { sajkui } \\ \text { ajpeku'norü } & \text { batir } & \text { anajpeku'noja } & \text { sajpeku'noi } \\ \text { akaamarü } & \text { dejar } & \text { anaakamaja } & \text { sakaamai } \\ \text { edaatorü } & \text { ponernombre } & \text { aneedatoja } & \text { sedaatoi } \\ \text { eduukuru } & \text { responder } & \text { aneedukuja } & \text { seduukui } \\ \text { eduuru } & \text { insultar } & \text { aneeduja } & \text { seedui } \\ \text { eneeporü } & \text { mostrar, indicar } & \text { aneenepoja } & \text { seneepoi } \\ \text { eneerü } & \text { ver, atender } & \text { aneeneja } & \text { seenei } \\ \text { eva'marü } & \text { besar } & \text { aneeva'maja } & \text { seva'mai } \\ \text { eva'nopüürü } & \text { gustar } & \text { aneeva'nopüja } & \text { seva'nopi } \\ \text { onoorü } & \text { comer } & \text { anoonoja } & \text { soonoi } \\ \text { orinsharü } & \text { voltear } & \text { anoorinshaja } & \text { sorinshai } \\ \text { ijpiurujkarü } & \text { pinchar } & \text { anijpiurujkaja } & \text { shijpiurujkai } \\ \text { ijshamoorü } & \text { verter } & \text { anijshamoja } & \text { shijshamoi } \\ \text { ijshanoororü } & \text { enfriar } & \text { anijshanooroja } & \text { shijshanooroi } \\ \text { ijshommiarü } & \text { mezclar, revolver } & \text { anijshommiaja } & \text { shijshommiai } \\ \text { ujkarü } & \text { descabezar } & \text { anujkaja } & \text { sujkai } \\ \text { ujkopootürü } & \text { multiplicar } & \text { anujkopootüja } & \text { sujkopooti } \\ \text { u'muerenkarü } & \text { rodear } & \text { anu'muerenkaja } & \text { su'muerenkai } \\ \text { u'mujkarü } & \text { inundar } & \text { anu'mujkaja } & \text { su'mujkai } \\ \text { u'narü } & \text { colar } & \text { anu'naja } & \text { su'nai } \\ \text { üppuorü } & \text { transformar } & \text { anüppuoja } & \text { süppuoi } \\ \text { üürü } & \text { dar, poner } & \text { anüürüja } & \text { süüri } \\ \text { waapirü } & \text { pisar } & \text { anuwwapija } & \text { suwaap(ü)i }\end{array}$




$\begin{array}{llll}\text { waanopüürü } & \text { bailar } & \text { anuwwanoopüja } & \text { suwwanoopi } \\ \text { waaponunkarü } & \text { adelantar } & \text { anuwwaaponunkaja } & \text { suwaaponunkai } \\ \text { wa'mijshorü } & \text { ablandar } & \text { anuwwa'mijshoja } & \text { suwa'mijshoi }\end{array}$

Consonante inicial de tema + prefijo an- + epéntesis + palatalización:

\begin{tabular}{llll} 
dooko-rü & cortar & an-i-yyokoja & sh-i-yooko-i \\
deerojtorü & herrar & aniyyeerojtoja & shiyeerojtoi \\
dejtorü & aflar & aniyyejtoja & shiyejtoi \\
kaanarojtorü & ganar & anijshaanarojtoja & shishaanarojtoi \\
kaapürü & tejer & anijshapüja & shishaapi \\
küüriñoorü & mover & anijshüüriñoja & shishüüriñoi \\
küürü & hacer, fabricar & anijshüürüja & shishüri \\
küürüntorü & equipar & anijshüürüntoja & shishüürüntoi \\
naarü & limpiar maleza & aniññaja & shiññai \\
nontarü & soltar & aniññontaja & shiñontai \\
raakamaarü & voltearalgo & aniyyaakamaja & shiyaakamai \\
raakarü & rajar, desgarrar & aniyyakaja & shiyaakai \\
raamarü & devolver & aniyyamaja & shiyaamai \\
rejputtorü & techar & aniyyejputtoja & shiyejputtoi \\
roomojkarü & ahogar & aniyyomojkaja & shiyoomojkai \\
saanontorü & amamantar & anijshaanontoja & shishaanontoi \\
saapakaarü & mojar, remojar & anijshaapakaja & shishaapakai \\
sujsunkarü & sacudir mata & anijshujsunkaja & shishujsunkai \\
suukumuaarü & revolver & anijshuukumuaja & shishuukumuai \\
sü'muarü & acechar & anijshü'muaja & shishü'muai \\
shiimijchuku'norü & acortar & anijshiimijchuku'noja & shishiimijchuku'noi \\
taarüjtorü & llenar & anitchaarüjtoja & shichaarüjtoi \\
taarükaarü & vaciar & anitchaarükaja & shichaarükai \\
tankarü & clavar & anitchankaja & shichankai \\
tüjkarü & asustar & anitchüjkaja & shichüjkai \\
\hline & & &
\end{tabular}

Consonante inicial de tema + prefijo an- + epéntesis + reflejo vocálico:

$\begin{array}{llll}\text { maanempa-rü } & \text { molestar } & \text { an-i-mmiaanempa-ja } & \text { sh-i-miaanempa-i } \\ \text { mojkarü } & \text { arrancar } & \text { animmiojkaja } & \text { shimiojkai } \\ \text { moomarü } & \text { echar } & \text { animmiomaja } & \text { shimioomai } \\ \text { münnoto'norü } & \text { embarazar } & \text { animmiünnoto'noja } & \text { shimiünnoto'noi } \\ \text { paakotoorü } & \text { herir, apuñalar } & \text { anippiaakotoja } & \text { shipiaakotoi } \\ \text { paanamaarü } & \text { ladear, voltear } & \text { anippiaanamaja } & \text { shipiaanamai } \\ \text { paaporü } & \text { botar, arrojar } & \text { anippiapoja } & \text { shipiaapoi } \\ \text { pajkarü } & \text { sacar } & \text { anippiajkaja } & \text { shipiajkai } \\ \text { pajporü } & \text { tumbarfruta } & \text { anippiajpoja } & \text { shipiajpoi } \\ \text { pijsharü } & \text { pelar } & \text { anippijshaja } & \text { shipijshai } \\ \text { pijshinsharü } & \text { salpicar } & \text { anippijshinshaja } & \text { shipijshinshai }\end{array}$




$\begin{array}{llll}\text { po'marü } & \text { encender } & \text { anippio'maja } & \text { shipio'mai } \\ \text { po'nomaarü } & \text { acomodar } & \text { anippio'nomaja } & \text { shipio'nomai } \\ \text { pookarü } & \text { flechar } & \text { anippiokaja } & \text { shipiookai } \\ \text { poomürü } & \text { poner, colocar } & \text { anippiomüja } & \text { shipioomi } \\ \text { pujpuonkarü } & \text { golpearla cabeza } & \text { anuppujpuonkaja } & \text { supujpuonkai } \\ \text { puutürü } & \text { conocer } & \text { anuuputüja } & \text { supuuti } \\ \text { püjtorü } & \text { casarahombre } & \text { anippiüjtoja } & \text { shipiüjtoi } \\ \text { pünnarü } & \text { apreciar, estimar } & \text { anippiünnaja } & \text { shipiünnai } \\ \text { vaarekaarü } & \text { cantar } & \text { anivviaarekaja } & \text { shiviaarekai } \\ \text { veenakaarü } & \text { vomitar } & \text { anivvieenakaja } & \text { shivieenakai } \\ \text { veenenaarojtorü } & \text { envenenar } & \text { anivvieenenaarojtoja } & \text { shivienenaarojtoi } \\ \text { vo'mükaarü } & \text { desvestirse } & \text { anivvio'mükaja } & \text { shivio'mükai } \\ \text { vo'müntorü } & \text { vestir } & \text { anivvio'müntoja } & \text { shivio'müntoi } \\ \text { voorü } & \text { matar } & \text { anivvioja } & \text { shivvioi } \\ \text { voovorü } & \text { lavar } & \text { anivviovoja } & \text { shivioovoi }\end{array}$

Aunque no ocurre con mucha frecuencia, este prefijo $3 \mathrm{O}$ an- en ocasiones puede omitirse si en la cláusula transitiva el objeto está expreso como una frase nominal. Ya tal posibilidad había sido anotada por Taradell (1774:286): "Para la practica, el an previo a los negativos [...] se puede omitir (pro libito), dexando para inicial la vocal que era herida por la $n$. V. g.: Apoypava, pro Anapoypava". En el siguiente ejemplo, podemos observar tal omisión:

(12)

$\begin{array}{lllll}\text { Dopooto } & \text { wüküürüdan } & \text { epoorüja } & \text { ne'i. } & \text { No: aneeporüja } \\ \text { dopoto } & \text { wükürü-yan } & \text { eporü-ja } & \text { n-ai-i } & \\ \text { jefe } & \text { hombre-plu } & \text { encontrar-neg } & \text { 3-estar-pas } & \\ \text { El jefe no encontró a los hombres. } & \end{array}$

\subsection{El prefijo derivativo i-}

El gerundio negativo de un verbo intransitivo no puede llevar un marcador de objeto, pero sí puede llevar un prefijo derivativo $i$ - para construir el tema negativo. Este prefijo $i$ - parece ser originalmente el prefijo de ' 3 ', aparentemente vaciado semánticamente de referencia a persona, como sucede en los "adjetivos" (cf. COURTZ, 2008, p. 126-127). Todavía no hemos podido dilucidar cuáles temas requieren este prefijo derivativo y cuáles no. Sin embargo, en aquellos que lo llevan, también son variados los resultados según su interacción con el tema verbal base:

Consonante inicial de tema base + prefijo $i-+$ metátesis (o reflejo vocálico + aféresis):

$\begin{array}{llll}\text { maanajtano } & \text { crecer senos } & \text { miaanajtaja } & \text { muaanajtai } \\ \text { monaatano } & \text { estar robando } & \text { mioonataja } & \text { moonatai } \\ \text { pootano } & \text { despedir olor } & \text { piootaja } & \text { puootai } \\ \text { poro'no } & \text { detenerse } & \text { piooropüja } & \text { puooropi } \\ \text { vareetano } & \text { cantar } & \text { viaaretaja } & \text { waaretai }\end{array}$


Consonante inicial de tema base + prefijo $i-$ + palatalización + aféresis:

$\begin{array}{llll}\text { kojtano } & \text { gritar } & \text { shojtaja } & \text { kojtai } \\ \text { renkotaano } & \text { cojear } & \text { yenkotaja } & \text { renkotai } \\ \text { romo'no } & \text { morir } & \text { yompüja } & \text { rüompi } \\ \text { shiññavaano } & \text { tocarinstrumento } & \text { shiññavaja } & \text { shiññavai } \\ \text { suuvitchano } & \text { ruborizarse } & \text { shuuvitchaja } & \text { suuvitchai } \\ \text { tüütü'wano } & \text { temblar } & \text { chüütü'waja } & \text { tüütü'wai }\end{array}$

Vocal a inicial de tema base + prefijo $i-+$ coalescencia $i+a \rightarrow e$ :

$\begin{array}{llll}\text { akajtunno } & \text { huir, escapar } & \text { ekajtumüja } & \text { düeekajtumi } \\ \text { aka'nano } & \text { correr } & \text { eka'naja } & \text { düeeka'nai } \\ \text { amaamiñaano } & \text { trabajar } & \text { emaamiñaja } & \text { düeemamimmiai } \\ \text { amanno } & \text { vivir, residir } & \text { emaamüja } & \text { düeemami } \\ \text { anuttano } & \text { despertarse } & \text { enuttaja } & \text { düeenuttai } \\ \text { atajtano } & \text { escupir } & \text { etajtaja } & \text { düeetajtai }\end{array}$

Tema base con prefijo $i$ - inicial en infinitivo y en tema negativo:

$\begin{array}{llll}\text { i'ñamootano } & \text { alegrarse } & \text { i'ñamootaja } & \text { ü'namootai } \\ \text { ijshanootano } & \text { enfriarse } & \text { ijshanootaja } & \text { üjkanootai } \\ \text { i'mia'no } & \text { acabarse } & \text { i'miatüja } & \text { ü'muati } \\ \text { i'mio'no } & \text { hervir } & \text { i'miotüja } & \text { ü'muoti } \\ \text { iññotaano } & \text { casarse(mujer) } & \text { iññotaja } & \text { üññotai }\end{array}$

Vocal a/e/u/ü inicial de tema base y tema negativo sin prefijo $i$-:

$\begin{array}{llll}\text { ake'manno } & \text { debilitarse } & \text { ake'mamüja } & \text { düaake'mami } \\ \text { apeetano } & \text { fructificar } & \text { apeetaja } & \text { düaapetai } \\ \text { ariyyunno } & \text { volar } & \text { ariyyumüja } & \text { düaariyyumi } \\ \text { aürüanaano } & \text { hablar } & \text { aürüanaja } & \text { daürüanai } \\ \text { avonno } & \text { pararse } & \text { avoomüja } & \text { düaavomi } \\ \text { e'vu'no } & \text { apagarse } & \text { e'vutüja } & \text { düe'vuti } \\ \text { ujshijshano } & \text { reunirse } & \text { ujchijchaja } & \text { dujshijchai } \\ \text { u'mu'no } & \text { inundarse } & \text { u'mutüja } & \text { nu'muti }\end{array}$

Consonante $w$ inicial de tema sin prefijo $i-$ :

$\begin{array}{llll}\text { weekano } & \text { defecar } & \text { weekaja } & \text { duwwekai } \\ \text { weetunnaano } & \text { darle sueño } & \text { weetunaja } & \text { duwwetunnai } \\ \text { we'majtano } & \text { hartarse } & \text { we'majtaja } & \text { duwwe'majtai } \\ \text { wükaano } & \text { decir } & \text { kaja } & \text { wükkai }\end{array}$


Temas destransitivizados sin prefijo $i$ - (y pérdida de $v$-):

$\begin{array}{llll}\text { vadu'no } & \text { responderse } & \text { aduukuja } & \text { vaduukui } \\ \text { vataakamaano } & \text { separarse } & \text { ataakamaja } & \text { vataakamai } \\ \text { vataarono } & \text { cazar, pasear } & \text { ataaroja } & \text { vataaroi } \\ \text { vatuttajkano } & \text { perderse } & \text { atuttajkaja } & \text { vatuttajkai } \\ \text { vavviovoono } & \text { lavarse } & \text { avviovoja } & \text { vavviovoi } \\ \text { vayyemaano } & \text { salvarse } & \text { ayyemaja } & \text { vayyemai } \\ \text { vayyokoono } & \text { cortarse } & \text { ayyokoja } & \text { vayyokoi } \\ \text { vekoorojkano } & \text { quemarse } & \text { ekoorojkaja } & \text { vekoorojkai } \\ \text { vekuupiño } & \text { bañarse } & \text { ekuupija } & \text { vekuupi } \\ \text { venaatano } & \text { vomitar } & \text { vieenataja } & \text { wenaatai } \\ \text { veraamano } & \text { regresar } & \text { eraamaja } & \text { veraamai }\end{array}$

\subsection{El sufijo o clítico negativo -ja}

En el kari'ña de Venezuela, el gerundio negativo de todos los verbos exhibe -ja como el alomorfo más común del morfema de negación. Sin embargo, aparecen otros alomorfos, tanto en algunas zonas kari'ñófonas de Venezuela, como en las variedades de la Guayana Francesa y Surinam. Pero en la misma Venezuela, esta forma con la fricativa glotal [ha] parece ser un desarrollo relativamente reciente, pues hace 250 años expresaba Taradell que la forma negativa se hacía con - $p a$.

A cada verbo afirmativo le corresponde su negativo, no por alguna negación suelta, como el no espanyol, el me betoyano, el di saliba, sino por esta diccion: pagua ô pava, [-pa=wa] que embevecida en el preterito del verbo, lo haze negativo, con variedad de tiempo y personas, segun la variedad del verbo gua ná (TARADELL, 1774, p. 285).

Asimismo, hace un siglo, Alvarado apuntaba que este morfema era spa, haciéndose a la vez eco de la opinión de que la forma negativa es un adjetivo:

Con razón dice el señor Goeje que puede considerarse el verbo negativo como un adjetivo. El procedimiento es el mismo de los nombres, por medio de la posposición spa. El verbo se conjuga entonces como los terminados en ba. Ejemplos: anarospaba [an-aaro-ja $=v a$ ] no lo llevo... (ALVARADO, 1919, p. 21).

Pero también en relatos recogidos hace pocas décadas en la población de Mamo, extremo sur del estado Anzoátegui de Venezuela, encontramos la forma -jpa (junto con -jpua, -jpüa, -jpia, que son producto del reflejo vocálico): 4

4. Es anómala la presencia de una j en el sufijo -ja. Las glotales tienen en kari'ña una distribución restringida y no ocurren ni al inicio ni al final de palabra. Los préstamos del español con fricativa glotal al inicio de palabra son adaptados sin tal glotal en la misma posición: jabón > kavoono). Las glotales en posición intervocálica son muy marcadas y ellas ocurren casi solamente en esta forma negativa y en el participio pasado. Las glotales intervocálicas pueden haber sido desarrollos recientes en kari'ña. La evidencia comparativa apunta en esta dirección, pues en las lenguas más cercanas genéticamente al kari'ña, el galibí de la Guayana Francesa (RÉNAULT-LÉSCURE, 1981, p. 75, p. 76) y el caribe de Surinam (HOFF, 1968, p. 140, p. 225), tales glotales intervocálicas están totalmente ausentes y los cognados exhiben o una $p$ o una secuencia xp: GAL oni:ki-pa, KAR o'nükü-ja 'sin dormir'; GAL an-e:ne-pa, KAR an-eene-ja 'sin ver'; CAR uwa-xpa, KAR wa-ja 'sin bailar'. Incluso dentro del kari'ña, encontramos casos donde hay variación entre una forma con j intervocálica y una forma con la secuencia jp: mashiipü 'largo', mashijpie mashihe /masipü-pe/ '(es) largo'. En futuras investigaciones se podrá determinar el estatus de estas glotales. 
(13)
Aduumükon
apiirüdanjdaano
adeenejpa
mantu.
a-dumü-kon
a-pirü-yan-jdaano
a-ene-jpa
mantu.
2-padre-COL
2-hermano-PLU-ENF 2-ver-NEG
3.estar.PLU

Ya no te van a ver más tus padres ni tus hermanos.

Además de esto, en el dialecto del kari'ña que nos ocupa, existen unos cinco verbos que en el gerundio negativo exhiben un alomorfo con palatalización -jsha. Es fácil entender que el desencadenante de la palatalización es la vocal $i$ final de tema. Lo que es menos claro es cómo una [h] puede sufrir palatalización. Como apunta un revisor anónimo, no parece una buena idea derivar una sh [ $\int$ ] de una /p/ subyacente, porque la oclusiva bilabial no debería palatalizarse sino simplemente exhibir reflejo vocálico, tal como es el caso de formas en -jpia del dialecto de Mamo. Una posible explicación es que dicha /p/ subyacente tuvo un recorrido primero como $[\phi]$, luego como [ç], para finalmente realizarse como [ $\int$ ]. Debe recordarse que en alemán, por ejemplo, [ç] es un alófono de $[\mathrm{x}]$, y en otras lenguas es alófono de /h/ en contacto con vocales anteriores. Estos verbos son:

$\begin{array}{llll}\text { apoyyü } & \text { agarrar } & \text { anaapo'ijsha } & \text { sapo'i } \\ \text { ayyü } & \text { ir por } & \text { ana'ijsha } & \text { sa'i } \\ \text { vataapoñño } & \text { agarrarse } & \text { ataapo'ijsha } & \text { vataapo'i } \\ \text { vatampoñño } & \text { menearse } & \text { atampo'ijsha } & \text { vatampo'i } \\ \text { vañño } & \text { estar } & \text { e'ijsha } & \text { ve'i }\end{array}$

Hay que destacar que este sufijo negativo bloquea los alargamientos de las vocales precedentes, aunque los mismos sean requeridos por el ritmo yámbico que opera en kari'ña. En los ejemplos que siguen, las sílabas están separadas por puntos y se agrupan en pies, indicados por paréntesis, mientras que <ja> indica que esta sílaba final es extramétrica. Las vocales en negritas son cabeza de pie yámbico y deberían ser alargadas:

\begin{tabular}{|c|c|c|c|}
\hline akaamarü & dejar & (a.naa).(ka.ma).<ja> & *(a.naa).(ka.maa).<ja> \\
\hline eduukuru & responder & (a.nee).(du.ku).<ja> & $*($ a.nee $) .(d u, k u u),<j a>$ \\
\hline eneeporü & mostrar & (a.nee).(ne.po).<ja> & *(a.nee).(ne.poo).<ja> \\
\hline kaapürü & tejer & (a.nij).(sha.pü).<ja> & *(a.nij).(sha.püü).<ja> \\
\hline vataakamaano & separarse & (a.taa).(ka.ma).<ja> & *(a.taa).(ka.maa).<ja> \\
\hline venaatano & vomitar & (viee).(na.ta). $<j a>$ & *(viee).(na.taa).<ja> \\
\hline
\end{tabular}

En kari'ña, las sílabas finales de las palabras son extramétricas y no pueden recibir alargamiento yámbico. Pero también existe un bloqueo general del alargamiento yámbico delante de [h], aunque de todos modos el número de palabras con una [h] intervocálica es mínimo (infinitivos pasados: adaarojo 'haberte llevado', düaatoküjo 'haberme cosido', kanajo 'habernos tenido; y préstamos del español: soorotija 'sortija', vojaro 'fósforo', ajo 'ajo', ejpejueero 'espejuelos', mavajitcha 'navajita', rajente 'gente'). De este modo, el no alargamiento puede ser atribuido: (a) a este bloqueo general, o (b) al hecho de que posiblemente -ja no forma una palabra con el tema verbal, por lo que la vocal corta lo es por estar en posición final extramétrica. También es posible pensar que este comportamiento se deba a que -ja probablemente no es un sufijo, sino un clítico. Para una visión más cabal de los fenómenos rítmicos en 
esta lengua, originadores de un rico alomorfismo (alargamientos vocálicos, geminación consonántica, palatalizaciones, etc.), remitimos a Álvarez (2004).

\title{
3. Una segunda aproximación a la negación clausal en kari’ña
}

Los trabajos de Mosonyi sobre el kari'ña (1982, 1986, 2000, 2002) versan principalmente sobre la morfología y el léxico, pero sus variados comentarios sintácticos nos permiten concluir que el autor percibió que el mecanismo básico de la morfosintaxis de la construcción negativa en esta lengua consiste en una forma negativa como base de toda la conjugación negativa, invariable en la flexión (exceptuando la expresión del objeto en verbos transitivos), mientras que la flexión se obtiene mediante su combinación con diversas formas del verbo vañño. Expresa Mosonyi que este tema verbal negativo "tiene un nítido valor predicativo" (1982:143), en el sentido de constituir el conjunto "una oración de predicado nominal" (1982:144). Es importante la conclusión que en este contexto ofrece el autor sobre la conjugación verbal, cuando recalca el crucial papel del verbo auxiliar vañño en este sistema y el carácter nominal de las formas negativas:

\begin{abstract}
Un estudio atento de la conjugación verbal en cariña tiende a demostrar que existe una gran abundancia de formas nominales, es decir, expresiones verbales que desde el punto de vista de su construcción y función sintáctica se asemejan a sustantivos y adjetivos, tanto atributivos como predicativos. Podríamos afirmar que las formas propiamente "verbales" de la conjugación son el presente, el pasado simple, (...) y el imperativo. Además, todas las subcategorías funcionan "verbalmente" cuando son afirmativas o declarativas, pues al hacerse negativas o interrogativas adquieren de inmediato el carácter nominal. (MOSONYI, 1986, p. 439. Énfasis nuestro, JA)
\end{abstract}

Según el análisis propuesto por Mosonyi, el sufijo -ja convertiría o transpondría una frase verbal (con o sin objeto según la valencia del verbo) en una forma nominalizada que ahora sería el predicado nominal de una cláusula con un sujeto intransitivo al cual estaría unido mediante el verbo "copulativo". Así, la oración (4a): Dopooto wüküürüdan epoorüja ne'i 'El jefe no encontró a los hombres', se analizaría: [Dopooto]S [[[wüküürüdan]O [epoorü]V]FV-ja]FN [ne'i]V.

Deseamos proponer aquí una interpretación alterna a la de Mosonyi. Suelen llamarse "verbos copulativos" a un pequeño número de verbos con referencia tan vaga y extensa que frecuentemente se les considera semánticamente vacíos (ser, estar, parecer, etc.) y que en la cláusula tienen un adyacente o complemento peculiar que en terminología española se denomina "atributo" y más comúnmente "predicado nominal". Este predicado nominal lo ocupa un sustantivo, un adjetivo o estructuras nominales más complejas que hacen concreta la vaga referencia del verbo copulativo. A veces se usa la expresión "predicado nominal" a la combinación del verbo copulativo y su atributo.

Como en kari'ña el verbo vañño nunca puede tener como complemento una frase nominal, estructuralmente el morfema negativo - ja realmente no nominaliza, sino que adverbializa la frase verbal, y es precisamente esta adverbialización la que permite tener dicha frase como complemento de dicho verbo vañño. Basaremos este análisis en otras propiedades sintácticas del kari'ña, ya que un mecanismo similar parece estar presente también en otras construcciones como las desiderativas, progresivas, posesivas, etc.

Hemos visto que en kari'ña existe una forma negativa con sufijo -ja añadido al tema verbal como base de toda la conjugación negativa, base que permanece invariable mientras que la flexión se expresa mediante las diversas formas del verbo vañño. Este tema verbal negativo, según Mosonyi (1982, p. 143) "tiene un 
nítido valor predicativo" en el sentido de constituir el conjunto "una oración de predicado nominal" (1982, p. 144, énfasis nuestro). Sin embargo, el mismo autor parece no sentirse cómodo con esta caracterización, puesto que simultáneamente sostiene que estas formas predicativas no son puramente nominales.

Nuestro análisis simplemente recoge la inquietud de Mosonyi y da un paso más allá en el sentido de afirmar que, al igual que este sufijo negativo "adverbializa" el verbo y ello permite tenerlo como complemento de dicho verbo vañño. Un análisis de la negación en otra lengua caribe en estos términos fue originalmente expuesto para el hixkaryana por Derbyshire (1985), y desarrollado también por Abbot (1991) para el makushi. En favor de esta interpretación hablan las traducciones alternas que da el mismo Mosonyi a ciertas formas negativas como: aneenaja ve'i 'yo no (lo) tuve' o 'sin tener(lo) estuve', e'ijsha me'i 'tú no fuiste' o 'sin ser estuviste', etc.

Nótese también que Mosonyi acierta en considerar funcionalmente parecidas el gerundio y esta forma negativa, que denomina "gerundio negativo", destacando su parecido con el gerundio español. Pero en español el gerundio es la forma adverbial del verbo. A diferencia del español, este gerundio kari'ña se caracterizar "en que posee plural y formas negativas" (MOSONYI, 1982, p. 12). El gerundio positivo, formado agregando -poko a una forma infinitiva, se combina con formas del verbo vañño 'estar' para dar origen a las formas progresivas, excepto en el presente. Según nuestro análisis, el denominado gerundio positivo es una frase posposicional aroorüpuooko /aro-rü=poko/ [llevar-NR=en] 'llevando', ekaamürüppuoko /ekamü-rü=poko/ [repartir-NR=en] 'repartiendo'. Por su parte, el gerundio negativo (esto es, la raíz del verbo con -ja) es también una adverbialización, por lo cual ambos son funcionalmente equivalentes.

Nuestro análisis se basa, además, en la relación de la negación con otros elementos clave de la sintaxis. En kari'ña existe un morfema especial me (con variantes), muy probablemente un cognado con pe del pemón, cuya función es convertir una forma nominal en predicativa, requerida obligatoriamente como complemento cuando se usa el verbo copulativo vañño, como en (14-15), y opcionalmente como adverbio modificando cualquier verbo no copulativo, como en (16):

(14)

\begin{tabular}{|c|c|c|c|}
\hline Mojse & atto & tumuutumueema. & *Mojse atto tumuutumua. \\
\hline mojse & atto & tumutu-me=ma & \\
\hline dem:1 & casa & blanca-ar=3.estar & \\
\hline
\end{tabular}

Esta casa es blanca.

(15)

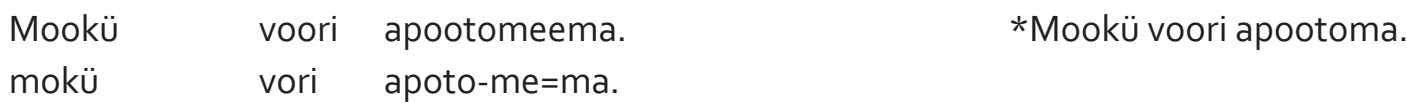

dem:3.an mujer alta-ar=3.estar

Aquella mujer es alta.

$\begin{array}{llll}\text { Mojse shipiyyu } & \text { sooreme } & \text { kono'najsa. } & * \text { *Mojse shipiyyu soore kono'najsa. } \\ \text { mojse shipiyu } & \text { sore-me } & \text { kVn-et-enapü-da } \\ \text { dem:1 niño } & \text { glotón-ar } & \text { 3-dtr-comer-pres } \\ \text { Este niño come golosamente. } & \end{array}$


El análisis de los constituyentes de (17) es, en lo esencial, [Mojse atto]S [tumuutu me]C [ma]V, donde el complemento [tumuutu me]C no puede aparecer sin me 'AR'. Este tipo de comportamiento lleva a Mosonyi (1986, p. 437) a dudar sobre el estatus de la noción "predicado nominal", ya afirma que en esta lengua "no hay diferencia entre predicado nominal y predicado verbal, o al menos que dicha diferencia sería de una naturaleza especial que habría que precisar". Es justamente ésta la precisión que ofrecemos: las cláusulas con el verbo "copulativo" son simplemente intransitivas y lo que en español constituye un predicado nominal no lo es en kari'ña (salvo en las cláusulas sin verbo), sino un complemento adverbial que requiere me u otra forma funcionalmente equivalente a un adverbio, como es el caso del tema negativo con -ja.

En Mosonyi (2000, p. 432), al hablar de los diferentes tipos de predicados, se presentan las oraciones de predicado nominal, divididas en dos tipos principales: adjetivales y sustantivas. En relación con las primeras, se afirma que en ellas "el adjetivo debe estar necesariamente en forma predicativa". Ahora bien, esta forma predicativa del adjetivo se forma fundamentalmente con me añadido al tema atributivo (que para las formas en $(14-16)$ se evidencian en atto aamu tumuutu 'una casa blanca', wüküürü aamu apooto 'un hombre alto' y shipiyyu aamu soore 'un niño glotón'), o con la modificación de la vocal final del mismo tema por $\boldsymbol{e}$ (esto es, $V>e$ ), como se observa en (17). Creemos que la llamada por Mosonyi "forma predicativa" es también una adverbialización que permite utilizar estas formas con el verbo vañño.

(17)
Na'na tü'namoorema.
na'na t-ü'namora-V>e=ma
pro:13 3r-alegre-ar=3.estar
Nosotros estamos alegres.

Más interesante todavía es que, al hablar de las oraciones en la que el predicado es nominal, se nos aclara (MOSONYI, 2000, p. 432) que "las formas de vañño (-ma, -va) no combinan directamente con el sustantivo predicado sustantival, sino con un pronombre o demostrativo, aunque este elemento tenga que repetirse en la oración."

\begin{tabular}{|c|c|c|c|}
\hline [Aau & eenarooro] $]_{S-P N}$ & [aauwa $_{\mathrm{S-v}}$ & *Aau eenaroorova. \\
\hline au & & $\mathrm{au}=\mathrm{wa}$ & \\
\hline PRO:1S & gobernador & PRO:1S=1.estar & \\
\hline
\end{tabular}

(19)

$\begin{array}{llll}\text { [Mojse } & \text { wüküürü } & \text { duumü }]_{S-P N} & \begin{array}{l}\text { [mojsema }_{S-V} . \\ \text { mojse=ma }\end{array} \\ \text { mojse } & \text { wükürü } & \text { Ü-dumü } & \text { *Mojse wüküürü duumümüa. } \\ \text { DEM:1 hombre } & \text { 1-padre } & \text { DEM:1=3.estar } & \end{array}$

Este hombre es mi padre. 
(20)

$\begin{array}{llll}{[\text { Kari'ña }} & \text { aaürüan düaaürüan }]_{S-P N}[\text { mooroma }]_{S-V} . & \text { *Kari'ña aaürüan düaaürüanmüa. } \\ \text { kari'ña } & \text { aüran ü-aüran } & \text { moro=ma } & \\ \text { kari'ña } & \text { lengua 1-lengua } & \text { DEM:2.INAN=3.estar } & \end{array}$

La lengua kariña es mi lengua.

(21)

\begin{tabular}{|c|c|c|c|c|}
\hline $\begin{array}{l}\text { [Amooro } \\
\text { amoro }\end{array}$ & $\begin{array}{l}\text { vüküürü] }]_{S-P N} \\
\text { vükürü }\end{array}$ & $\begin{array}{l}\text { [amooro } \\
\text { amoro }\end{array}$ & $\begin{array}{l}\text { maana }]_{S-V} \cdot \\
\text { mana }\end{array}$ & *Amooro vüküürü maana. \\
\hline & hombre & PRO:2 & 2.estar & \\
\hline
\end{tabular}

Tú eres hombre.

Interpretamos esta obligatoria repetición de la siguiente manera. En kari'ña la sintaxis impide decir, por ejemplo, 'yo soy gobernador' a secas, porque así 'gobernador' sería un predicado nominal del verbo vañño 'estar' cuyo sujeto es 'yo'. Este impedimento no es exclusivamente fonológico, ya que las formas monosilábicas del verbo vañño, va y $m a$, son clíticos de cualquier palabra a su izquierda en la cláusula. Así, además de Na'na tü'namoorema 'Nosotros estamos alegres' en (20), con el verbo vañño cliticizado al "adjetivo" tü'namoore, también se puede decir Tü'namoorema na'nama, con el verbo vañño cliticizado al pronombre na'na. El impedimento es sintáctico, ya que no existen realmente cláusulas de predicado nominal (sustantival) con el verbo vañño, que es, digámoslo una vez más, un verbo intransitivo y no un verbo copulativo a la manera del español o el inglés. Así, no se puede decir *Aau eenaroorova lau eenaroro=va/ [yo gobernador=1.estar]. La solución desarrollada en kari'ña es entonces la yuxtaposición de dos cláusulas, la primera arremática 'yo gobernador', la segunda es una intransitiva con el verbo vañño 'yo estoy'. El verbo vañño, normalmente cliticizable, está en otra cláusula y no puede en este contexto unirse fonológicamente al constituyente de una cláusula diferente de la suya. ${ }^{5}$

En (22-25) se ofrecen oraciones negativas extraídas de textos donde se evidencia, con ayuda de traducciones más literales entre paréntesis, el carácter adverbial del tema negativo al que acompaña el verbo vañ̃̃o está en diferentes formas.

\begin{tabular}{|c|c|c|c|}
\hline $\begin{array}{l}\text { Eerome } \\
\text { erome } \\
\text { ahora }\end{array}$ & $\begin{array}{l}\text { mürejti } \\
\text { mürejti } \\
\text { muchachos }\end{array}$ & $\begin{array}{l}\text { pentü anajkuja } \\
\text { pentü an-ajku-ja } \\
\text { faldilla } 30 \text {-usar-neg }\end{array}$ & $\begin{array}{l}\text { mantu. } \\
\text { man-tu } \\
\text { 3.estar-plu }\end{array}$ \\
\hline
\end{tabular}

5. Siguiendo el Programa Minimalista, en Medina (2002, p. 141-144) se analizan, a nuestro juicio erróneamente, oraciones del tipo ilustrado en (21-24) como si la frase nominal que es predicado de la primera cláusula formara un constituyente FD con el pronombre/demostrativo que es sujeto de la segunda cláusula. Bajo esta interpretación, tendríamos una sola cláusula y vañño admitiría predicados nominales. Así, uno de los ejemplos que ofrece, Pedro dopooto aamu mojko man 'Pedro es un jefe', es analizado como si los elementos en negritas formaran un constituyente: $\left[_{\mathrm{FD}}[\mathrm{Pedro}]_{\mathrm{FV}}\left[{ }_{\mathrm{FD}}\left[{ }_{\mathrm{D}}{ }_{\mathrm{F}}\left[\mathrm{FN}_{\mathrm{F}}\left[\right.\right.\right.\right.\right.$ dopooto ${ }_{\mathrm{D}}[$ aamu $\left.]\right]$ $\left.\left.\left.{ }_{\text {Esp }}[\mathrm{mojko}]\right]_{\mathrm{v}}[\mathrm{man}]\right]\right]$. 
(23)

$\begin{array}{lllll}\text { O'makon } & \text { eerupuaatoko } & \text { tünnonorükkon } & \text { aneepemaapoja } & \text { natchojse. } \\ \text { a-'ma-kon } & \text { erupa-to-ko } & \text { t-nono-rü-kon } & \text { an-epema-po-ja } & \text { n-ai-to-se } \\ \text { 2-hijo-col } & \text { decir-plu-imp } & \text { rf-tierra-pos-col } & \text { 30-pagar-cau-neg } & \text { 3-estar-plu-sup } \\ \text { Hablen a sus hijos para que no vendan sus tierras. (Lit. [...] que sus tierras sin.vender estén.) }\end{array}$

(24)

$\begin{array}{lll}\text { Yujpummue } & \text { anuuputüjaññe } & \text { kataatu. } \\ \text { yujpun-me } & \text { an-uputü-ja-ine } & \text { kVs-ai-tu } \\ \text { bueno-AR } & \text { 30-saber-NEG-PLU } & \text { 1+2-estar-PLU } \\ \text { No los conocemos bien. (Lit. Bien sin.conocerlos estamos.) }\end{array}$

(25)

$\begin{array}{lll}\text { Yujpummue } & \text { wejponoorü } & \text { anuuputüjava. } \\ \text { yujpun-me } & \text { uvejpono-rü } & \text { an-uputü-ja=wa } \\ \text { bueno-AR } & \text { nadar-POS } & \text { 30-saber-NEG=1.estar } \\ \text { Yo no sé nadar } & \text { muy bien. (Lit. Bien nadar sin.saberlo estoy.) }\end{array}$

El morfema negativo (transpositor a adverbio) es tratado como un sufijo por algunos y como una posposición por otros. Hablando del kari'ña, Mosonyi dice: "Se afirma con frecuencia que las lenguas caribes son posposicionales, y ello hasta cierto punto es cierto. Sin embargo, más que de posposiciones debemos hablar de sufijos" (MOSONYI, 1986, p. 440). Es nuestro parecer que los factores rítmicos han oscurecido la discusión, de modo que muy probablemente los que se consideran sufijos no sean sino posposiciones cliticizadas. En favor de esta idea está el hecho de que el proceso de reducción silábica, tan masivo en estas lenguas (ÁLVAREZ, 2004), puede usarse de manera diagnóstica para distinguir entre sufijos y clíticos. La reducción silábica opera en el interior de palabra y por ellos los sufijos la desencadenan, pero los clíticos no. Si no hay reducción silábica, en las lenguas caribes probablemente sea mejor considerar ciertos "sufijos" como posposiciones cliticizadas. Como ya el mismo Mosonyi había intuido en sus traducciones literales de construcciones negativas, -ja posiblemente sea una posposición equivalente a la preposición española sin.

En (26-40) presentamos un amplio muestrario de oraciones negativas en kari'ña con diferentes construcciones y categorías donde, pese a la heterogeneidad de los contextos, se evidencia el mecanismo común que hemos indicado para la formación de la negación clausal.

$\begin{array}{llll}\text { Aau } & \text { epajkajava, } & \text { mojko'roopa } & \text { epajkajama. } \\ \text { au } & \text { epajka-ja=va } & \text { mojko-'ropa } & \text { epajka-ja=ma } \\ \text { PRO:1S } & \text { salir-NEG=1.estar } & \text { DEM:3.an-ADIC } & \text { salir-NEG=3.estar }\end{array}$

(27)

$\begin{array}{llll}\text { Tuduumü } & \text { aürüan } & \text { anüürüja } & \text { ne'i. } \\ \text { t-dumü } & \text { aüran } & \text { an-ürü-ja } & \text { n-ai-i } \\ \text { RF-padre } & \text { palabra } & \text { 3O-dar-NEG } & \text { 3-estar-PAS } \\ \text { Él no cumplió la palabra de su (propio) padre. } & \end{array}$


(28)

$\begin{array}{ll}\text { Aau } & \text { adaamojshajava. } \\ \text { au } & \text { a-amojsha-ja=va } \\ \text { PRO:1S } & \text { 2-creer-NEG=1.estar } \\ \text { Yo no te creo. } & \end{array}$

(29)

Morookompoko atuupijava.

moro-kon-poko at-upi-ja=va

DEM:2.INAN-COL-en dTR-buscar-NEG=1.estar

No me preocupo por esas cosas.

(30)

$\begin{array}{lll}\text { Mojko } & \text { voori } & \text { eneerüsejava. } \\ \text { mojko } & \text { vori } & \text { ene-rü-se-ja=va } \\ \text { DEM:2.ANI } & \text { mujer } & \text { ver-NR-DES-NEG=1.estar }\end{array}$

No quiero ver a esa mujer.

(31)
Kaürüanko
anuttajkaja
katajshen.
k-aüran-kon
an-utajka-ja
kVt-ai-sen
12-lengua-COL
3O-perder-NEG
12-estar-PLU
No pierdan su lengua.

(32)

Aneeneja wayyümua.

an-ene-ja $\quad w$-ai-rü=ma

3O-ver-NEG 1-estar-NR=3.estar

No lo voy a ver.

(33)
Tanüjke
e'ijsha
we'ijshoto,
düaavomüürümuaanompoma.
t-anükü-ke
ai-ja
w-ai-joto
Ü-avomü-rü-manompo=ma
RF-enfermedad-con estar-NEG 1-estar-CONDI 1-levantar-NR-POTEN=3.estar
Si no estuviera enfermo, me levantaría ahora mismo.

(34)

$\begin{array}{lllll}\text { Aau } & \text { seerupua'mai } & \text { mooro } & \text { anijshüürüja } & \text { yatcho'me. } \\ \text { au } & \text { s-erupa'ma-i } & \text { moro } & \text { an-kürü-ja } & \text { i-ai-to'me } \\ \text { PRO:1S } & \text { 1/3-convencer-PAS } & \text { DEM:2.INAN } & \text { 30-hacer-NEG } & \text { 3-estar-FINAL } \\ \text { Yoloconvencíde que no hiciera eso. } & & \end{array}$


(35)

Mookü voori apootome e'ijshama.

mokü vori apoto-me ai-ja=ma

DEM:3.ANI mujer alto-AR estar-NEG=3.estar

Aquella mujer no es alta.

(36)

Tapeenejkopoore chootokon e'ijsha mantu kari'ñakon viñño.

t-epe-na-V>e-jkopore itoto-kon e'i-ja man-tu kari'ña-kon vino

RF-valor-NR-AR-COMP criollo-COL estar-NEG 3.estar-PLU cariña-COL desde

Los criollos se consideran más valiosos que los indígenas.

(37)

Ü'wa aniyyamaanojpoja natchu.

ü-'va an-rama-nojpo-ja n-ai-tu

1-por 3O-devolver-CAU-NEG 3-estar-PLU

Ellos no me dejaron devolverlo.

(38)

Mieeriyoorü senaae, epeemarüsejateko'neva.

i-meriyo-rü s-ena-e epema-rü-se-jateko'ne=va

3-dinero-POS 1/3-tener-PRES pagar-NR-DES-ADVERS=1.estar

Tengo su plata, pero no quiero pagarle.

(39)

Aau chojava tanüjke wayyükke.

au to-ja=va t-anükü-ke w-ai-rü-ke

PRO:1S ir-NEG=1.estar RF-enfermedad-con 1-estar-NR-con

Yo no voy porque estoy enfermo.

(40)

$\begin{array}{lll}\text { Amooro } & \text { duuputüja } & \text { maana? } \\ \text { amoro } & \text { u-uputü-ja } & \text { mana } \\ \text { PRO:2 } & \text { 1-conocer-NEG } & \text { 2.estar }\end{array}$

¿Tú no me conoces?

\section{La negación clausal en otras lenguas caribes}

La expresión de la negación clausal con construcciones paralelas ha sido reportada en otras lenguas caribes: galibí (RÉNAULT-LESCURE, 1981), tamanaco (GILIJ, 1782), hixkaryana (DERBYSHIRE, 1985), makushi (ABBOTT, 1991), y pemón (ÁLVAREZ, 2000), entre otras. Nos ocuparemos de presentar datos de estas cinco lenguas para destacar el paralelismo de los fenómenos discutidos. Los datos del pemón se discutirán al final de esta sección más extensamente, mientras que los datos de las otras lenguas se presentarán de modo más compacto. En algunas ocasiones usaremos traducciones forzadas, de 
mayor elocuencia ilustrativa, para visualizar más claramente las estructuras. Este paralelismo debería tenerse en cuenta para el avance en el estudio comparativo de las lenguas caribes, tal como ha sido magistralmente iniciado en Gildea (1998). El tema de la comparación de la negación en las lenguas de la familia arahuaca ha sido tratado en Michael \& Granadillo (2014). En dicho volumen llama la atención la diversidad de estructuras negativas dentro de esa familia, diversidad que no sorprende habida cuenta de la extensión geográfica y la diversidad tipológica de la familia. Estos datos que aquí presentamos de lenguas de la familia caribe hacen suponer una expresión más uniforme, posiblemente por su menor extensión geográfica y su mayor homogeneidad tipológica.

\subsection{Galibi}

Rénault-Lescure (1981) afirma que en esta lengua, muy cercana al kari'ña, el enunciado negativo "est formé sur le schéma de l'énoncé à prédicat verbal" ["está formado bajo el esquema del enunciado de predicado verbal"] y añade que "le prédicat est un adjectif dérivé par suffixation d'un morphème de négation à un verbe ou un nom" ["el predicado es un adjetivo derivado por sufijación de un morfema de negación a un verbo o un nombre"] (p. 175). Precisa además que este sufijo adjetiviza un verbo transitivo, "le suffixe de négation apparaît conjointement avec un préfixe qui se réfère a l'objet (...) ce préfixe personnel peut être explicité dans une projection nominal" ["el sufijo de negación aparece juntamente con un prefijo que se refiere al objeto (...) este prefijo personal puede ser explicitado en una proyección nominal"] (p. 176). En (41) se ofrece un ejemplo de cláusula negativa con el verbo léxico intransitivo, mientras que en (42-43) se ilustra la negación clausal con verbos léxicos transitivos.

$(41)$

$\begin{array}{ll}\text { Onüüküpa } & \text { man. } \\ \text { onükü-pa } & \text { man } \\ \text { dormir-NEG } & \text { 3.estar } \\ \text { Él no duerme. } & \end{array}$

$(42)$

$\begin{array}{ll}\text { Aneenepa } & \text { wa. } \\ \text { an-ene-pa } & \text { wa } \\ \text { 3O-ver-NEG } & \text { 1.estar } \\ \text { Yo no lo veo. } & \end{array}$

(43)

$\begin{array}{lll}\text { Kaleeda } & \text { anukuutüpa } & \text { man } \\ \text { kaleda } & \text { an-ukutü-pa } & \text { man } \\ \text { libro } & \text { 3O-conocer-NEG } & \text { 3.estar }\end{array}$

Él no conoce libros.

Esta autora, como vemos, ofrece un análisis paralelo al de Mosonyi al considerar que en estas cláusulas negativas "le prédicat est un adjectif dérivé [es decir, es una nominalización, JA] par suffixation d'un morphème de négation" ["el predicado es un adjetivo derivado por sufijación de un morfema de negación"]. De esta manera, las oraciones en (44-46) tendrían una forma aproximada Sujeto Cópula - Cláusula Nominalizada ('no-V-nte'): 'Él es no-durmiente', 'Yo soy no-vidente (de) él', 'Él es no-conociente (de) libros.' 


\subsection{Tamanaco}

Hace más de doscientos años, el misionero italiano Filippo Salvatore Gilij escribió su obra Ensayo de Historia Americana, en la que documentó diversas lenguas americanas, en particular la lengua maipure y la tamanaca, ésta de filiación caribe. De la lectura de la edición española de 1965 entresacamos datos y observaciones que muestran el paralelismo con el kari'ña y el galibí. Analizamos en (44) uno de los ejemplos ofrecidos por Gilij (1965(3), p. 178) para evidenciar la construcción de la negación clausal.

(44)

$\begin{array}{lll}\text { Caramanári } & \text { anacreprá } & \text { machíi. } \\ \text { Ø-karamana-ri } & \text { an-akre-pra } & \text { m-achi-i } \\ \text { 1-palabra-POS } & \text { 3O-observar-NEG } & \text { 2-estar-PAS }\end{array}$

No has observado mi palabra.

En relación con la negación clausal, destaca este autor que la forma verbal negativa, lograda mediante el elemento pra, es un complemento del verbo copulativo:

Son muy extraños y en nada conformes a nuestro modo de hablar los verbos negativos. En tamanaco no se dice no veo, no oigo, etc., sino no soy vidente, no soy oyente, etc. He aquí los ejemplos: eneprá vochíi, anitaprá uochíi, etc. (GILIJ, 1965(3), p. 152).

Como puede deducirse de las traducciones literales que ofrece Gilij ('no soy vidente, no soy oyente'), este autor también consideró que en las cláusulas negativas tamanacas hay una especie de nominalización (ver > vidente) que sirve de predicado con un verbo copulativo. El ejemplo (44) tendría, pues, una forma Sujeto - Cópula - Cláusula Nominalizada ('no-V-nte'): 'Fuiste no-observante (de) mi palabra.'

\subsection{Hixkaryana}

La negación clausal en hixkaryana, lengua caribe brasileña estudiada por Derbyshire (1985), también tiene gran parecido con el kari'ña. Sin embargo, este autor nos ofrece una interpretación diferente del fenómeno. En la negación clausal en esta lengua, el verbo léxico toma una forma adverbial que se obtiene con la posposición negativa -hira usada como transpositor, mientras que los elementos de la flexión van todos en la cópula. "This dummy auxiliary construction is the only way of constructing negative sentences" ["Este auxiliar comodín es la única manera de construir oraciones negativas"] ( $p$. 138). La oración en (45) ilustra esta negación clausal en hixkaryana.

$\begin{array}{lllll}\text { Apaytara } & \text { yari } & \text { hira } & \text { nexeye } & \text { wekoko. } \\ \text { apaytara } & \text { yari } & \text { hira } & \text { nexeye } & \text { wekoko } \\ \text { pollo } & \text { agarrar } & \text { NEG } & \text { 3.estar.PAS } & \text { águila }\end{array}$

El águila no agarró los pollos.

El ejemplo (45), visto de esta manera, tendría, pues, una forma Sujeto - Cópula - Cláusula Adverbializada ('no V-ndo'): 'El águila estaba no agarrando los pollos' (sin matiz progresivo) [[Apaytara yari] hira] nexeye wekoko]. 


\subsection{Makushi}

En Abbott (1991, p. 55-59, p. 80) se discute la negación de constituyentes y la negación de cláusulas. En los ejemplos (46) y (47) de Abbott (1991) se ilustra la construcción, donde wai y wanî́pî son formas del verbo auxiliar. Nótese que en esta construcción se observa morfosintaxis ergativa en el interior de las cláusulas transitivas transpuestas en adverbiales, ya que los sujetos de las cláusulas transitivas están marcados por el sufijo de ergativo -ya:

$\begin{array}{llll}\text { Waikin } & \text { era'mauya } & \text { pra } & \text { wai. } \\ \text { waikin } & \text { era'ma-u-ya } & \text { pra } & \text { wai } \\ \text { venado } & \text { ver-1-ERG } & \text { NEG } & \text { 1.estar } \\ \text { No vi el venado. } & {[161 \mathrm{~b}] \text { de Abbott }}\end{array}$

(47)

$\begin{array}{llllll}\text { Itakon } & \text { wanî'pî } & \text { tîrui } & \text { maimu } & \text { yuukuiya } & \text { pra. } \\ \text { it-akon } & \text { wanî-'pî } & \text { tî-rui } & \text { maimu } & \text { yuuku-i-ya } & \text { pra } \\ \text { 3-hermano } & \text { estar-PAS } & \text { RF-hermano } & \text { palabra } & \text { responder-3-ERG } & \text { NEG } \\ \text { El hermano no obedeció la palabra de su hermano mayor. [279] de Abbott } & \end{array}$

De manera semejante a Derbyshire, en relación con la negación de cláusulas afirma que el mecanismo de su formación es la partícula negativa que transpone la cláusula en un complemento adverbial del verbo copulativo:

Negation of a sentence is accomplished by the negative particle pra occurring following the clause and transforming it into a negative adverbial complement of the copula. The inflectional affixes marking tense, aspect, and number appear on the copula. The subject-marking affixes occur on the subordinate verb. (ABBOTT, 1991, p. 56)

Los ejemplos (46-47), vistos de esta manera, tendrían también una forma Sujeto - Cópula - Cláusula Adverbializada ('no V-ndo'): 'Estoy no viendo el venado' [[Waikin era'mauya] pra] wai] y 'El hermano estuvo no obedeciendo la palabra de su hermano mayor' [Itakon wanî́pî [[tîrui maimu yuukuiya]] pra]. Nótese que el verbo copulativo, como intransitivo que es, no exhibe morfología ergativa. De manera semejante a Derbyshire, en relación con la negación de cláusulas afirma que el mecanismo de su formación es la partícula negativa que transpone la cláusula en un complemento adverbial del verbo copulativo.

\subsection{Pemón}

Existe en pemón una partícula püra que claramente es una forma cognada del kari'ña -ja, del galibí - pa, del tamanaco - pra, del hixkaryana hira y del makushi pra. Ésta puede utilizarse para la negación parcial, esto es, en la negación de constituyentes de la cláusula, tales como adverbios y frases posposicionales, pero también se utiliza para la negación total de la cláusula en combinación con el verbo copulativo echi 'estar'. Es de observar que, en estos casos, el negador püra actúa como una posposición que convierte en subordinada circunstancial la cláusula precedente. Internamente ésta puede ser intransitiva (48), o transitiva y exhibir entonces morfología ergativa (el sujeto de la cláusula transitiva está marcado por el sufijo -ya de ergativo) (49). En ambos casos el verbo echi es el verbo principal de una cláusula 
intransitiva matriz que contiene otra cláusula con su propia transitividad. De esta manera, la negación del predicado con püra da lugar a una construcción intransitiva con el verbo echi como verbo principal, mientras que la cláusula cerrada con püra pasa a ser transpuesta a una forma adverbial complemento de dicho verbo.

(48)

$\begin{array}{lll}\text { l'tö püra } & \text { i'chi'pö. } \\ \text { i-etö püra } & \text { i-esi-'pö } \\ \text { 3-ir NEG } & \text { 3-estar-PAS } \\ \text { Él no se fue. } & \end{array}$

(49)

$\begin{array}{llll}\text { I'ko'wanto' } & \text { putuya } & \text { püra } & \text { echi. } \\ \text { i-ko'wamüto' } & \text { putu- } \varnothing \text {-ya } & \text { püra } & \varnothing \text {-esi } \\ \text { 3-morada } & \text { saber-1-ERG } & \text { NEG } & \text { 1-estar } \\ \text { No conozco su morada. } & & \end{array}$

Nótese que en pemón el verbo copulativo echi no es un verbo copulativo en el sentido usual que este término tiene en español. Formalmente se comporta como un verbo intransitivo cualquiera, pudiendo predicar simple existencia (Pemon echi'pö 'Había/Érase un pemón'). Por esta razón, podemos pensar que existen en pemón solamente los siguientes tipos de cláusula: (1) transitivas (con orden de constituyentes AOV/OVA), con la cláusula de cita como un subtipo especial; (2) intransitivas (con orden de constituyentes SV), con la cláusula estativa/copulativa como un subtipo especial; (3) ecuativas o cláusulas de predicado no verbal, en las cuales está ausente el verbo, y sólo están presentes como constituyentes una frase nominal sujeto y una frase nominal predicado en un orden que varía según factores de focalización. (cf. ÁLVAREZ, 2000).

En todos estos tipos de cláusulas puede haber opcionales constituyentes periféricos. En las cláusulas estativas/copulativas el verbo echi es el verbo por excelencia, aunque con menor frecuencia puede serlo también enan 'volverse'. Además de los constituyentes obligatorios (el sujeto y el verbo echi), con la excepción de la simple predicación de existencia, se presentan también como constituyentes frases descriptivas. Sin embargo, es importante destacar que en pemón no es posible que dicha frase descriptiva sea exhaustivamente ocupada por una frase nominal.

Esto quiere decir que en pemón, con el verbo echi 'estar, ser' y enan 'volverse' literalmente no se pueden construir cláusulas del tipo 'Pedro es/era/será [grande/maestro/esposo de María, etc.]', porque dichas frases nominales en corchetes no pueden desempeñar por sí solas, como sí lo pueden en español, el oficio de complementos de cláusulas estativas/copulativas (aunque sí pueden cumplir dicha función como predicado en una ecuativa o cláusula de predicado no verbal: Pemon yuurö 'Yo soy pemón', literalmente 'pemón yo'). No existe en pemón una clase de adjetivos, sino simplemente nombres descriptivos, y éstos no pueden aparecer solos con los verbos echi y enan como sus complementos. Para poder decir 'yo era pemón' usando el verbo echi y no en una cláusula arremática (sin verbo), hay que decir Pemon pe echi'pö. Esto se ilustra bellamente en (50) mediante las palabras que Jesús, en un relato recogido por Armellada (1973), dice en pemón a un araguato que se empeña en que debe rezar en lo alto de un árbol. 
(50)

$\begin{array}{lllllll}\text { Pootorüto } & \text { Mumu pe echi'ma, pemon } & \text { pe } & \text { nörö } & \text { echi. } \\ \text { Pootorüto } & \text { mum-ü pe esi-ima pemon } & \text { pe } & \text { nörö } & \varnothing \text {-esi } \\ \text { Dios } & \text { hijo-POS AR } & \text { estar-SIM persona } & \text { AR } & \text { también } & \text { 1-estar }\end{array}$

Siendo Hijo de Dios, yo también soy hombre.

Como se puede observar doblemente en (50), el recurso utilizado en pemón para poder complementar el verbo copulativo es la adverbialización de la frase nominal mediante la posposición pe 'ADVERBIALIZADOR' (AR). En otros contextos estas formas constituidas por una frase nominal seguida por pe son traducidas por 'como', 'a la', o por adverbios en -mente. En resumen, como el verbo echi no puede tomar como complemento una frase nominal, en la cláusula negativa en la que se emplea püra como negador y dicho verbo como auxiliar, tiene que interpretarse estructuralmente como que püra transpone la cláusula subordinada como un adverbial y no como una frase nominal.

\section{Conclusiones}

Aunque es patente la gran semejanza en la construcción negativa en estas lenguas caribes, hay una marcada dualidad en los análisis que han ofrecido los autores de la estructura de dicha construcción en las lenguas que describen. Unos autores, entre ellos Mosonyi, consideran que el tema negativo es una nominalización auxiliada con un verbo copulativo, mientras que para otros autores se trata de una adverbialización. Gilij piensa que en el tamanaco la forma verbal negativa formada por la adición del elemento pra es un complemento nominal del verbo copulativo. De esta manera, las traducciones literales que ofrece del tipo 'no oigo = no soy oyente', hacen pensar que concibió dicha forma verbal negativa como una nominalización. Otro tanto sucede con el análisis de Rénault-Lescure para el galibí, ya que según ella estamos en presencia de una adjetivación (nominalización) de un verbo.

Muy probablemente el kari'ña -ja, el galibí - pa, el tamanaco - pa, el hixkaryana hira, el makushi pra y el pemón püra son formas cognadas. Tal relación de cognados la asume, por ejemplo, Meira (2003) en su discusión de la negación en la lengua yukpa, añadiendo también las formas equivalentes en las lenguas wayana, waiwai, apalaí.

Pero además de esta relación genética, parece obvio también que todas estas formas actúan como transpositores en el sentido de que ellas degradan una cláusula y la transponen funcionalmente a una unidad de rango inferior, habilitándola para funciones distintas a las propias de su categoría, esto es, convirtiéndola en equivalente funcional de sustantivos, adjetivos o adverbios (ALARCOS, 1994, p. 226-227). En el caso de este elemento transpositor en las lenguas caribes, las evidencias aportadas apuntan a considerarlo como un adverbializador. No parece existir en estas lenguas un verbo copulativo que permita tener un predicado nominal. Los verbos que usualmente son presentados como auxiliares copulativos deben ser considerarlos como núcleos de predicados intransitivos que sólo toman complementos adverbiales. Estas consideraciones deberían pasar a formar parte del estudio comparativo de las construcciones negativas en lenguas caribes. Al contrario de la diversidad de estructuras negativas dentro de la familia arahuaca reportada en Michael \& Granadillo (2014), los datos que aquí presentamos de lenguas de la familia caribe hacen suponer una expresión más uniforme, posiblemente por su menor extensión geográfica y su mayor homogeneidad tipológica. Es evidente, sin embargo, que para asegurarse de tal uniformidad hay que incluir aquellas lenguas caribes 
más alejadas del Escudo Guayanés y que no están representadas en este estudio, aunque los datos aportados por Meira (2003) sobre la construcción negativa en yukpa, que también tiene una estructura de origen copular, nos permiten ser optimistas al respecto.

\section{Referencias}

ABBOT, Miriam. Macushi. En DERBYSHIRE, Desmond; PULLUM, Geoffrey (Eds.). Handbook of Amazonian languages, vol. 3. Berlín: Mouton de Gruyter, 1991, pp. 23-160.

ALARCOS LLORACH, Emilio. Gramática de la lengua española. Madrid: R.A.E. - Espasa-Calpe, 1994. ALVARADO, Lisandro. Observaciones sobre el caribe hablado en los llanos de Barcelona. Caracas: Tipografía Americana, 1919.

ÁLVAREZ, José. Split ergativity and complementary distribution of NP's and pronominal affixes in Pemón Cariban. Opción, n. 25, pp. 70-94, 1998.

ÁLVAREZ, José. Construcciones progresivas en pemón y otras lenguas caribes. Opción, v. 32. pp. 96130, 2000.

ÁLVAREZ, José. Syllable reduction and mora preservation in Kari'ña. Amérindia, v. 28. pp. 55-82, 2004.

ARMELLADA, Cesáreo de. Taurón Pantón II Así dice el cuento. Caracas: Universidad Católica Andrés Bello, 1973 .

COURTZ, Henk. A Carib grammar and dictionary. Toronto: Magoria Books, 2008.

DERBYSHIRE, Desmond. Hixkaryana and Linguistic Typology. Arlington, Texas: Summer Institute of Linguistics and the University of Texas at Arlington, 1985.

GILDEA, Spike. On Reconstructing Grammar. Comparative Cariban Morphosyntax. Oxford: Oxford University Press, 1998.

GILIJ, Filippo Salvatore. Ensayo de historia americana. 3 vols. Caracas: Biblioteca de la Academia Nacional de la Historia, 1965. Trabajo original publicado en 1782.

GIVÓN, Talmy. Syntax. An introduction. Vols. I y II. Amsterdam: John Benjamins, 2001.

HOFF, Berend. The Carib Language. Verhandelingen van het Koninklijk Instituut voor Taal-, Land-en Volkenkunde, No 55. [Nijhoff, The Hague] Dordrecht and Providence: Foris, 1968.

MATTÉI-MÜLLER, Marie-Claude. Diccionario ilustrado panare-español. Índice español-panare. Un Aporte al estudio de los panare-e'ñepa. Con la colaboración de Paul Henley y Prajedes Salas. Caracas: Comisión Nacional Quinto Centenario, 1994.

MEDINA TAMANAICO, Pedro; MOSONYI, Jorge. Kaareta toorupuamü kari'ña aürüanta. Libro de lectura en idioma kari'ña. Caracas: Ministerio de Educación, 1982.

MEDINATAMANAICO, Pedro; MOSONYI, Jorge. Dos Cuentos Kariñas. Boletín de Lingüística, v. 3, pp. 10-18, 1984.

MEDINA, Raimundo. Aspectos del verbo vañño y otras configuraciones intransitivas en kari'ña. Omnia, v. 8, n. 1-2, p. 127-148, 2002. 
MEIRA, Sérgio. Primeras observaciones sobre la lengua yukpa. Lingua Americana, v. 7, n. 12, p. 113$138,2003$.

MICHAEL, Lev; Tania GRANADILLO (Eds.). Negation in Arawak Languages. Leiden/Boston: Brill, 2014. MIESTAMO, Matti. Standard Negation: The Negation of Declarative Verbal Main Clauses in a Typological Perspective. Berlín: Mouton de Gruyter, 2005.

MOSONYI, Esteban; MOSONYI, Jorge. Manual de lenguas indígenas de Venezuela. Caracas: Fundación Bigott, 2000.

MOSONYI, Jorge. Morfología verbal del idioma cariña. Trabajo de grado de Maestría en Lingüística, Universidad Central de Venezuela, Caracas, 1982.

MOSONYI, Jorge. Algunos problemas referentes a la interpretación de las categorías morfológicas de la lengua cariña. Kari'ña, familia caribe, Venezuela. In ROJAS, M. T. (Ed.). Actas del V Congreso Internacional de la Asociación de Lingüística y Filología de la América Latina ALFAL. Caracas: Universidad Central de Venezuela, 1986, pp. 433-441.

MOSONYI, Jorge. Kariña (Kari'ña). In MOSONYI, Esteban; MOSONYI, Jorge. Con la colaboración de Pedro Medina Tamanaico, 2000, pp. 398-450.

MOSONYI, Jorge. Diccionario básico del idioma kari'ña. Barcelona Venezuela: Fondo Editorial del Caribe y Gobernación del Estado Anzoátegui, 2002.

PAYNE, Thomas. Describing morphosyntax: A guide for field linguists. Cambridge: Cambridge University Press, 1997.

RÉNAULT-LESCURE, Odile. Evolution lexicale du Galibi, langue caraïbe de la Guyane Française. Thése pour le doctorat, Paris: ORSTOM-TDM-F, 1981.

TARADELL, Martín de. Vocabulario de Español a Caribe. In: Lenguas de América. Manuscritos de la Real Biblioteca, volumen I. pp. 213-305, 1774 .

TAUSTE, Francisco de. Arte, y bocabvlario de la lengva de los indios chaymas, cvmanagotos, cores, parias, y otros diversos de la Provincia de Cvmanà, ò Nveva Andalvcia. Madrid: Imprenta de Bernardo de Villadiego, 1680. 